\title{
Clinical prognostic significance of cancer stem cell markers in patients with papillary thyroid carcinoma
}

\author{
YOON-JONG RYU ${ }^{1}$, JI-YOUNG CHOE ${ }^{2}$, KYOUNGYUL LEE ${ }^{3}$ and SOON-HYUN AHN ${ }^{4}$ \\ ${ }^{1}$ Department of Otorhinolaryngology, Kangwon National University School of Medicine, Chuncheon, \\ Gangwon 24341; ${ }^{2}$ Department of Pathology, Hallym University Sacred Heart Hospital, Anyang, Gyeonggi 14068; \\ ${ }^{3}$ Department of Pathology, Kangwon National University Hospital, Chuncheon, Gangwon 24289; ${ }^{4}$ Department of \\ Otorhinolaryngology, Head and Neck Surgery, Seoul National University College of Medicine, \\ Seoul National University Hospital, Seoul 03080, Republic of Korea
}

Received December 6, 2018; Accepted July 5, 2019

DOI: $10.3892 / \mathrm{ol} .2019 .11087$

\begin{abstract}
The recent development of the cancer stem cell (CSC) model has been heralded as a new era in thyroid cancer research. The aim of this study was to evaluate the presence of $\mathrm{CD}^{+} 4^{+}$and $\mathrm{CD} 24^{-}$tumor cells in papillary thyroid carcinoma (PTC) as markers of aggressiveness and poor prognosis. Patients with PTC, who underwent successful surgical resections between January 2003 and December 2012 at a single tertiary hospital, were included in this study. Tissue arrays were prepared from 454 primary tumor tissues. Immunohistochemistry (IHC) was performed to detect the CSC markers CD24 and CD44 on the tissue arrays. IHC was graded using a semi-quantitative histology scoring system based on the extent and intensity of staining. Subsequently, the association between IHC results and clinicopathological characteristics and recurrence-free survival (RFS) was analyzed. In 454 patients, 39 cases recurred during the 70-month median follow-up period, with some patients exhibiting multiple sites of relapse. The results of a Kaplan-Meier survival analysis and univariate log-rank test demonstrated that sex $(\mathrm{P}=0.008)$, age $(\mathrm{P}=0.002)$, cN1b, defined as metastasis to unilateral, bilateral, or contralateral neck lymph nodes or retropharyngeal lymph nodes $(\mathrm{P}<0.001), \mathrm{pN} 1$, defined as pathologically proven lymph node metastasis $>5(\mathrm{P}<0.001)$, tumor size $>2 \mathrm{~cm}(\mathrm{P}<0.001)$, extrathyroidal extension $(\mathrm{P}=0.001)$ and $\mathrm{CD} 24^{-}(\mathrm{P}<0.001)$ were prognostic factors for RFS. CSC marker combinations $\left(\mathrm{CD} 44^{+} / \mathrm{CD} 24^{-}\right)$also exhibited statistical significance in the log-rank test. In conclusion, expression of the CSC markers $\mathrm{CD}_{4}{ }^{+}$and $\mathrm{CD} 24^{-}$in PTC tissue samples was associated with RFS. The combination of $\mathrm{CD} 44^{+}$and $\mathrm{CD} 24^{-}$exhibited
\end{abstract}

Correspondence to: Professor Soon-Hyun Ahn, Department of Otorhinolaryngology, Head and Neck Surgery, Seoul National University College of Medicine, Seoul National University Hospital, 101 Daehak-ro, Jongno-gu, Seoul 03080, Republic of Korea

E-mail: ahnsh30@snu.ac.kr

Key words: papillary thyroid carcinoma, cancer stem cell, immunohistochemistry, CD44, CD24 a statistically significant negative association with RFS and a strong association with gross extra-thyroidal extension.

\section{Introduction}

Thyroid carcinoma is the most common endocrine malignancy, and its incidence has increased globally in recent decades (1). In Korea, thyroid carcinoma diagnoses have also risen rapidly, accounting for $14.2 \%$ of all cancer cases in 2014 (2). Papillary thyroid carcinoma (PTC) accounts for the majority of the newly diagnosed cases (3). PTC has a very good prognosis; however, even after appropriate treatment, $10-20 \%$ of patients experience recurrence, with 2-5\% developing distant metastases between several years and several decades following treatment (4). Since a number of patients who experience recurrence eventually succumb to cancer, the establishment of prognostic factors for recurrence is an important part of PTC treatment.

The cancer stem cell (CSC) theory attracted interest when it was first introduced in the 1990s as a novel target for potential curative treatment for cancer (5). However, the discovery that CSCs have plasticity and may exhibit a reversible phenotype with non-CSCs, along with the observation that CSCs are not a rare population in tumors, makes this theory complicated and difficult to adopt in clinical practice. Despite these limitations, the CSC theory still has clinical relevance, as these cells are believed to be able to sustain or generate new tumors. In our previous study in collaboration with the MD Anderson Cancer Center, CD44+/CD24- were proposed as phenotypic markers for CSCs in PTC (6). However, since PTC is insufficiently aggressive to generate new cancers in animal models, the tumorigenic potential of PTC CSCs could not be proven. The present study aimed to define the prognostic significance of CD44 and CD24 expression using immunohistochemistry (IHC) on samples from patients with PTC, in order to identify the clinical significance of these CSC markers.

\section{Materials and methods}

Patients and tissue samples. Between July 2003 and December 2012, PTC samples were collected from 500 patients with PTC (tumor size, $>1 \mathrm{~cm}$ ) that underwent successful surgical 
resection at Seoul National University Bundang Hospital; these samples were analyzed in this retrospective study. Patients who received prior treatment or could not commit to 6 months of follow-up care were excluded. This study was approved by the Institutional Review Board at Seoul National University Bundang Hospital (approval no. B-1507/306-310). Previously prepared paraffin blocks of surgical specimens were examined by two pathologists. Paraffin blocks of primary tumor tissues were not available for 46 of the 500 patients; therefore, samples from 454 patients were selected for the generation of tissue microarrays (TMAs). The clinicopathological characteristics of the patients are summarized in Table I.

TMA. Following the review of 454 tumor tissues, representative core tissue sections (diameter, $2 \mathrm{~mm}$ ) were extracted from the paraffin blocks and arranged in new TMA blocks using a trephine apparatus (Superbiochips Laboratories), according to the manufacturer's protocol. The TMA blocks were sectioned into $4-\mu \mathrm{m}$ slices for IHC.

IHC staining. This study evaluated the expression of two proteins in tumor tissues: CD44 and CD24. The following antibodies were used: Rabbit monoclonal anti-CD44 (1:600; Boster Biological Technology Co., Ltd.; cat. no. PA1021-2) and mouse monoclonal anti-CD24 (1:50; Abcam; cat. no. MA5-11833). Using the Discovery XT automated IHC instrument (Ventana Medical Systems, Inc.), the sections were stained using the following procedures. Firstly, detection was performed using a Ventana Chromo Map kit (Ventana Medical Systems, Inc.). Sections were deparaffinized using an EZ Prep solution included in the Chromo Map kit. CC1 standard (Tris, borate and EDTA buffer; $\mathrm{pH}$ 8.4) was used for antigen retrieval (at $95^{\circ} \mathrm{C}$ for $44 \mathrm{~min})$. Treatment with Inhibitor $\mathrm{D}\left(3 \% \mathrm{H}_{2} \mathrm{O}_{2}\right)$ for $4 \mathrm{~min}$ at $37^{\circ} \mathrm{C}$ was used to block endogenous peroxidase. Sections were then incubated with primary antibodies for $32 \mathrm{~min}$ at $37^{\circ} \mathrm{C}$ and with an OmniMap anti-mouse secondary antibody (Ventana Medical Systems, Inc.; cat. no. 760-4310) for $20 \mathrm{~min}$ at $37^{\circ} \mathrm{C}$. Sections were incubated in 3,3'-diaminobenzidine $+\mathrm{H}_{2} \mathrm{O}_{2}$ substrate for $8 \mathrm{~min}$ at $37^{\circ} \mathrm{C}$, followed by hematoxylin and eosin reagent counterstain for $2 \mathrm{~min}$ at $37^{\circ} \mathrm{C}$. Reaction buffer (Tris buffer; $\mathrm{pH}$ 7.6) was used as a washing solution. Slides were evaluated on a Zeiss Axioskop light microscope (Carl Zeiss) equipped with Zeiss Plan-Neofluar objective lenses (x40, x200).

IHC grades. Immunostaining was evaluated by two independent pathologists, who were blind to the experimental design, and the IHC scores were determined semi-quantitatively based on staining intensity and proportion. IHC expression was graded according to the following staining intensity criteria: 0 , no staining; 1 , weak staining; 2 , moderate staining; and 3 , strong staining.

Tonsils from children undergoing tonsillectomy were used as a positive control (Fig. 1) (7). Tissues that scored $\leq 1$ were considered negative (-), whereas $>1$ was marked as positive (+) for statistical analysis (Fig. S1)

Statistical analysis. SPSS software (version 19.0; IBM Corp.) was used for statistical analysis. Pearson's $\chi^{2}$ test was used to analyze the relationship between protein expression and clinicopathological data. Recurrence-free survival (RFS) was
Table I. Clinicopathological characteristics of the patients $(n=454)$.

\begin{tabular}{|c|c|c|}
\hline Variable & Median (range) & $\mathrm{N}(\%)$ \\
\hline \multicolumn{3}{|l|}{ Sex } \\
\hline Male & & 107 (23.6) \\
\hline Female & & $347(76.4)$ \\
\hline Age at surgery, years & $48.0(10-87)$ & \\
\hline$<60$ & & $92(20.3)$ \\
\hline$\geq 60$ & & $362(79.7)$ \\
\hline $\mathrm{cN} 1 \mathrm{~b}$ & & $94(20.7)$ \\
\hline \multicolumn{3}{|l|}{ pN1 } \\
\hline$\leq 5$ & & $351(77.3)$ \\
\hline$>5$ & & $103(22.7)$ \\
\hline \multicolumn{3}{|l|}{ T stage } \\
\hline $\mathrm{T} 1$ & & $101(22.2)$ \\
\hline $\mathrm{T} 2$ & & $14(3.1)$ \\
\hline $\mathrm{T} 3$ & & $332(73.1)$ \\
\hline $\mathrm{T} 4$ & & $7(1.5)$ \\
\hline Pathological tumor size, $\mathrm{cm}$ & $1.4(1.0-7.0)$ & \\
\hline$\leq 2$ & & $332(73.1)$ \\
\hline$>2$ & & $122(26.9)$ \\
\hline Multifocality & & $204(44.9)$ \\
\hline \multicolumn{3}{|l|}{ Extrathyroidal extension } \\
\hline No & & $117(25.8)$ \\
\hline Microscopic & & $235(51.8)$ \\
\hline Macroscopic & & $102(22.5)$ \\
\hline \multicolumn{3}{|l|}{ Surgery } \\
\hline Lobectomy/total & & $21 / 433$ \\
\hline thyroidectomy & & $(4.6 / 95.4)$ \\
\hline $\mathrm{CND} / \mathrm{CND}+\mathrm{LND}$ & & $\begin{array}{c}281 / 96 \\
(61.9 / 21.1)\end{array}$ \\
\hline \multicolumn{3}{|l|}{ First relapse } \\
\hline Thyroid remnant or bed & & $3(0.7)$ \\
\hline Central compartment LN & & $5(1.1)$ \\
\hline Lateral compartment LN & & $27(5.9)$ \\
\hline Distant site & & $8(1.8)$ \\
\hline Time to first relapse, months & $22(2-101)$ & \\
\hline Follow-up time, months & $70(6-141)$ & \\
\hline \multicolumn{3}{|l|}{ Death } \\
\hline Cancer & & $0(0)$ \\
\hline Other causes & & $2(0.4)$ \\
\hline
\end{tabular}

CND, central compartment neck dissection; LN, lymph node; LND, lateral compartment neck dissection; $\mathrm{T}$ stage, pathologic Tumor-Node-Metastasis $\mathrm{T}$ stage (American Joint Committee on Cancer, 7th edition) (21).

determined based on the positive and negative expressions of proteins using Kaplan-Meier survival analysis and univariate log-rank test. In addition, a multivariate Cox regression test was performed to identify factors affecting RFS. P $<0.05$ was considered to indicate a statistically significant difference. 


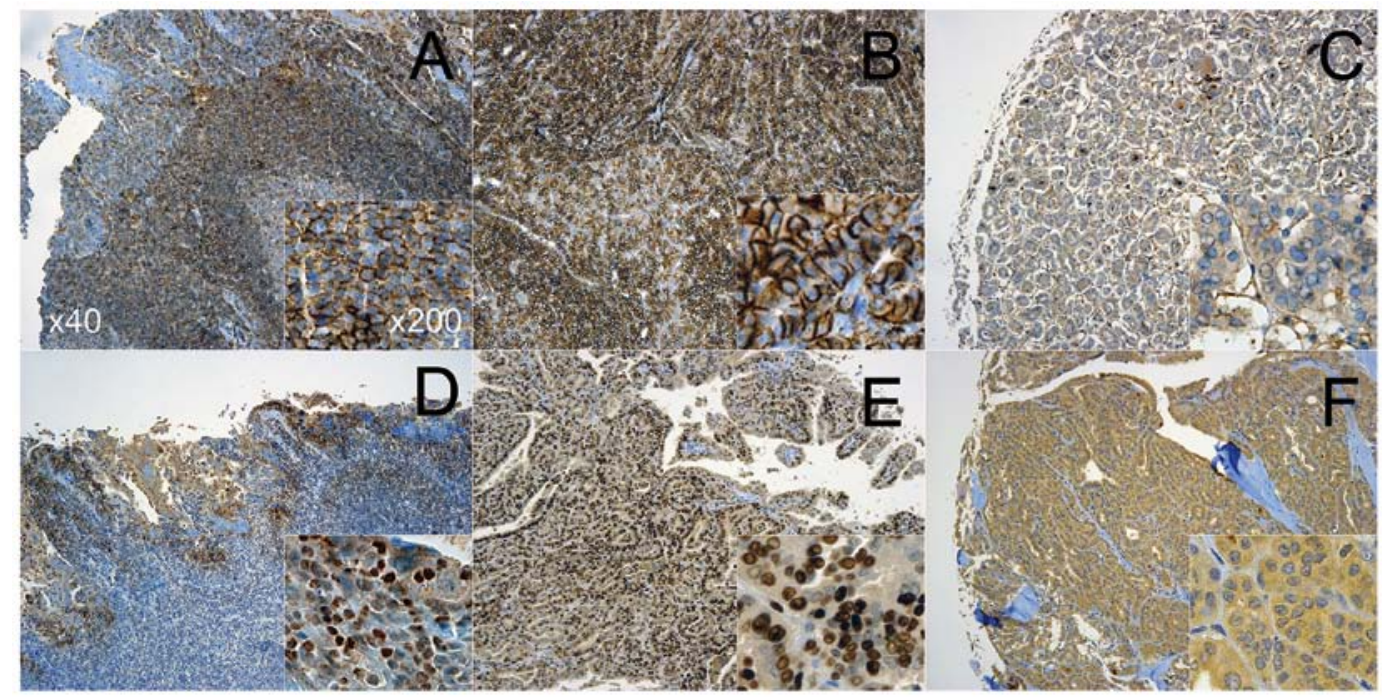

Figure 1. Immunohistochemical staining pattern of papillary thyroid carcinoma. (A) CD44 positive control from a human tonsil. (B) CD44+. (C) CD44(D) $\mathrm{CD} 24$ positive control from a human tonsil. (E) CD24+. (F) CD24-

\section{Results}

Patient clinicopathological characteristics. A total of 454 patients with PTC were included in this study. Relevant demographic, clinical and pathological data, as well as management and survival data of the patients were retrieved and summarized in Table I. A higher number of female compared with male patients with PTC [female, 347 (76.4\%) vs. male, $107(23.6 \%)]$ were enrolled. Their age ranged between 10 and 87 (median, 48.0) years. A total of 92 patients (20.3\%) were $<60$ years old, whereas the remaining 362 patients (79.7\%) were $\geq 60$ years old. Of the 454 patients, 94 (20.7\%) were suspected to have lateral lymph node metastasis at the time of diagnosis (cN1b). Histopathologically, 351 patients (77.3\%) exhibited $\leq 5$ lymph node metastases, whereas 103 patients (22.7\%) exhibited $>5$ lymph node metastases. According to the Tumor-Node-Metastasis (TNM) staging system (8), 101 patients (22.2\%) were classed as T stage 1, $14(3.1 \%)$ as stage $2,332(73.1 \%)$ as stage 3 and seven as stage $4(1.5 \%)$. There were 332 patients $(73.1 \%)$ with primary tumor diameters $\leq 2 \mathrm{~cm}$ in size and 122 patients $(26.9 \%)$ with tumor diameters $>2 \mathrm{~cm}$; 204 (44.9\%) patients exhibited multifocality. A total of 117 patients $(25.8 \%)$ did not exhibit an extrathyroidal extension, 235 (51.8\%) exhibited a microscopic extrathyroidal extension and 102 (22.5\%) exhibited a gross extrathyroidal extension. Total thyroidectomy was performed in the majority of patients (95.4\%). Central lymph node dissection was performed in 377 patients $(83.0 \%)$, of which 96 patients $(21.1 \%)$ also underwent lateral lymph node dissection. The median follow-up period was 70 months and two patients were lost to the follow-up due to unrelated causes. PTC recurred in 39 (8.6\%) patients, with certain patients exhibiting multiple instances of recurrence in different locations. The median time to first recurrence was 22 months. Recurrence sites were as follows: Three cases in the thyroid remnant or bed, five cases in the central lymph node area, 27 cases in the lateral lymph node area and eight cases of distant metastases.
Association of IHC results with clinical data in patients with PTC. The majority of clinicopathological characteristics did not demonstrate a statistically significant association with single CSC markers; however, age $(\mathrm{P}=0.001)$, extrathyroidal extension $(\mathrm{P}=0.039)$ and cancer recurrence $(\mathrm{P}<0.001)$ exhibited a significant association with CD24 expression (Table II).

Associations of the combined status of CD44+ and CD24 with clinicopathological data in patients with PTC were also determined. A statistically significant association was identified between the recurrence of cancer for all combinations of CSC markers. Particularly, the combination of $\mathrm{CD} 44^{+} / \mathrm{CD} 24^{-}$exhibited a significant association with age and gross extrathyroidal extensions (Table II).

RFS according to clinical data and IHC. RFS curves according to clinical data and IHC results are presented in Fig. 2. As determined using Kaplan-Meier survival analysis and univariate log-rank test, sex $(\mathrm{P}=0.008)$, age $(\mathrm{P}=0.002)$, cN1b $(\mathrm{P}<0.001), \mathrm{pN} 1>5(\mathrm{P}<0.001)$, tumor size $>2 \mathrm{~cm}(\mathrm{P}<0.001)$, extrathyroidal extension $(\mathrm{P}=0.001)$ and $\mathrm{CD}^{-} 4^{-}(\mathrm{P}<0.001)$ were prognostic factors for RFS. The CSC marker combination $\mathrm{CD} 44^{+} / \mathrm{CD} 24^{-}$also exhibited statistical significance in the log-rank test. In multivariate analysis, $\mathrm{CD} 44^{+} / \mathrm{CD} 24^{-}$was identified as an independent prognostic factor for PTC with a hazard ratio of 4.207 (Table III).

\section{Discussion}

Cancer prognosis and treatment efficacy are ultimately determined by survival of the patient, and the criteria for staging are based on factors related to survival. However, in the case of a differentiated thyroid carcinoma, cancer progression is very slow (9); therefore, even in the case of recurrence, a cure is possible following further operations and treatment with radioactive iodine (10). If thyroid carcinoma is not cured, a long and considerable period of palliative care may follow. Therefore, in the case of differentiated thyroid carcinoma, the prognosis 


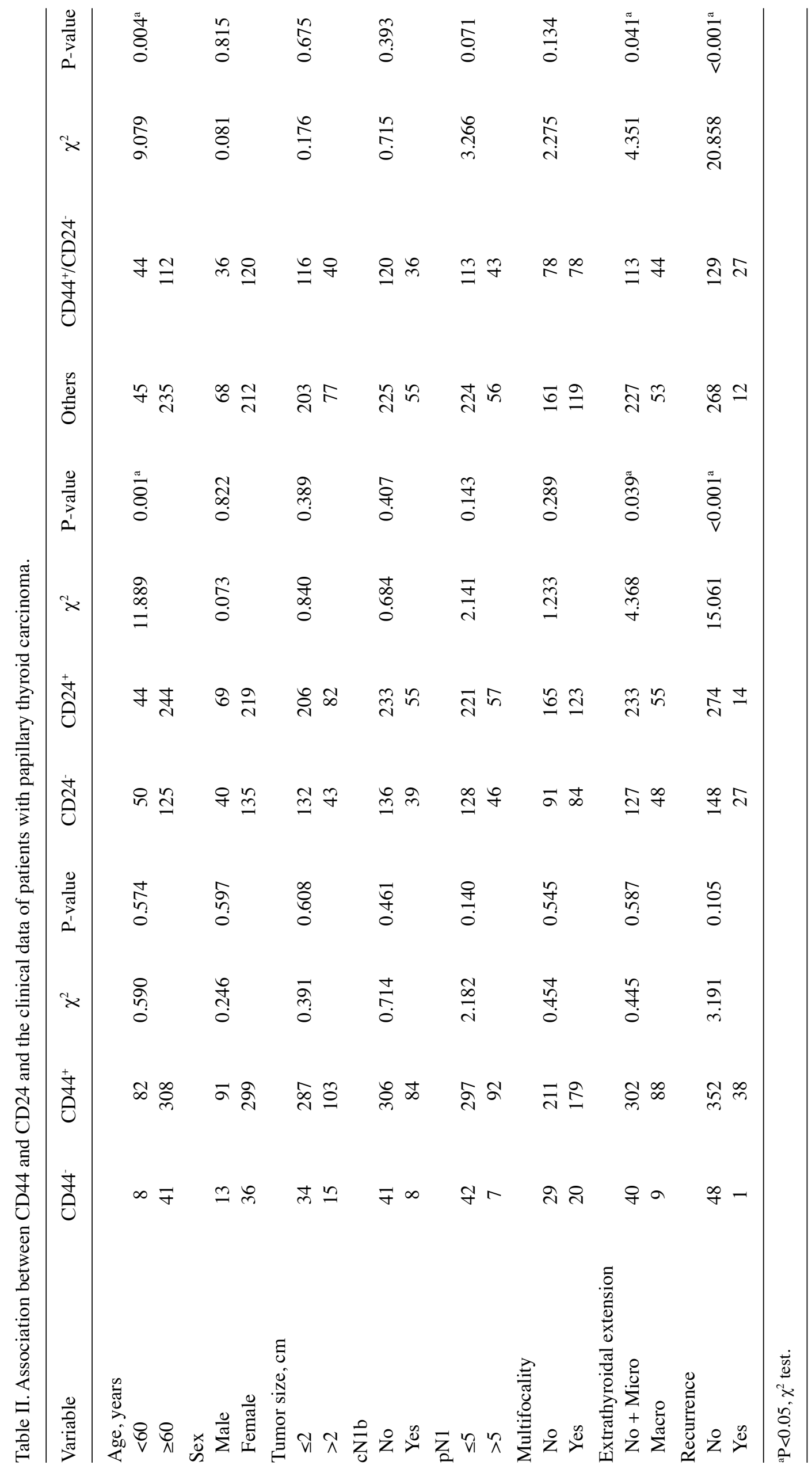



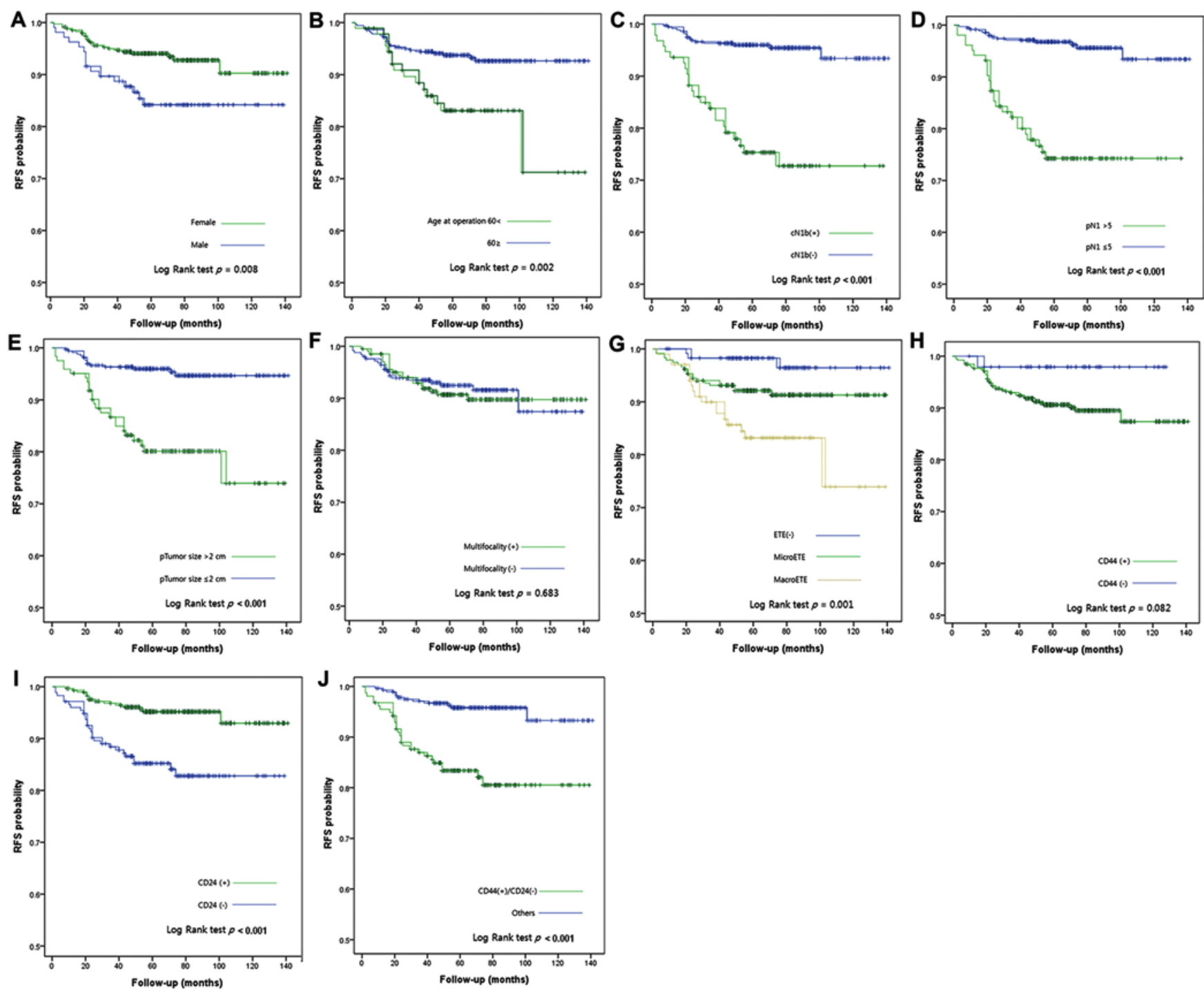

Figure 2. Kaplan-Meier plots of RFS according to clinical data and immunohistochemistry. RFS plots based on (A) sex; (B) age at surgery; (C) cN1b stage;

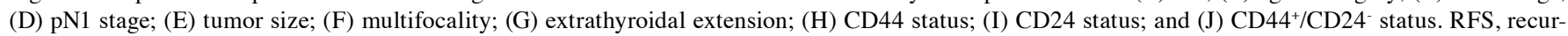
rence-free survival.

may not be determined based on survival alone; instead, analyzing RFS may be a more reasonable approach (11). In the present study, no patients succumbed to PTC during the 70-month median follow-up period, and the recurrence rate was $8.6 \%$, similar to previous prognostic studies $(3,12)$.

Thyroid CSCs can be distinguished by the expression of specific biomarkers, the ability to produce thyrospheres in vitro and the ability to induce tumors in vivo (13). Zito et al (14) first attempted to isolate CSCs in 2008 by analyzing the expression of CD133 through flow cytometry in thyroid cancer cell lines. Subsequently, Friedman et al (15) demonstrated that the transplantation of $\mathrm{CD} 133^{+}$cells into immunodeficient NOD/SCID mice is sufficient to induce tumor growth in vivo. Our previous study on CSCs focused on CD44 and CD24, which are CSC markers for certain cancers, including breast and colon cancer (16). Using specific cancer cell lines (TPC-1 and its derivatives), higher numbers of CD $44^{+} / \mathrm{CD} 24^{-}$cells have been identified in more aggressive cell lines (positivity rates: $86 \%$ in highly tumorigenic TPC-1 mouse cells; $>73 \%$ in moderately tumorigenic TPC-1SC2 cells; and $>21 \%$ in parental, poorly tumorigenic TPC-1 cells) (4). Subsequently, $4-70 \%$ of dispersed cells from thyroid cancers have been determined to be CD $44^{+} / \mathrm{CD} 24^{-}$. These cells form spheres; however, $\mathrm{CD} 44^{+} / \mathrm{CD} 24^{-}$, but not $\mathrm{CD} 44^{+} / \mathrm{CD} 24^{+}$cells from these spheres are spherogenic. The cells derived from thyrospheres $\left(\geq 1 \times 10^{4}\right)$ form tumors following orthotopic injection in an immunodeficient mice model (6). However, the impact of these markers on clinical outcome could not be assessed in the previous study. Therefore, the present study used PTC surgical specimens in TMAs to conduct standardized IHC experiments.

To the best of our knowledge, the present study is the first to analyze the association between CD44 and CD24 expression status and the clinical prognosis of PTC. The results of the present study demonstrated that the expression of CD44 or CD24, as determined by IHC, was not associated with commonly known prognostic factors in patients with PTC, with the exception of the presence of gross extrathyroidal extension. Recently, the American Joint Committee on Cancer (AJCC) 8th edition for thyroid cancers downstaged 
Table III. Multivariate analysis of recurrence-free survival.

\begin{tabular}{lccc}
\hline Variable & Hazard ratio & $95 \%$ CI & P-value \\
\hline Age $(>60)$ & 1.911 & $0.937-3.895$ & 0.075 \\
Sex (male) & 2.262 & $1.174-4.359$ & $0.015^{\text {a }}$ \\
Size $(>2 \mathrm{~cm})$ & 2.576 & $1.200-5.527$ & $0.015^{\mathrm{a}}$ \\
cN1b & 2.606 & $0.909-7.474$ & 0.075 \\
pN1 $(>5)$ & 2.426 & $0.858-6.861$ & 0.095 \\
Gross ETE & 1.259 & $0.573-2.769$ & 0.566 \\
CD44 $/$ CD24- & 4.207 & $2.088-8.479$ & $<0.001^{\text {a }}$ \\
\hline
\end{tabular}

${ }^{\mathrm{a}} \mathrm{P}<0.05$, Cox regression analysis. $95 \% \mathrm{CI}, 95 \%$ confidence interval; ETE, extrathyroidal extension.

a large number of patients by raising the age at diagnosis cut off from 45 to 55 years (8). This change was confirmed by the identification of a good prognosis in patients aged between 45 and 55 years in an international multi-institutional validation study of 9,484 patients (17). Similarly, in the present study, a difference in IHC outcome and prognostic analysis at index age 45 years was not observed (data not shown). However, when the index age was raised to 60 years, differences in $\mathrm{CD}_{4} 4^{+} / \mathrm{CD} 24^{-}$expression status and prognosis were detected.

A significant association between RFS and CD24 expression was identified using Kaplan-Meier analysis. CD44 exhibited an association with RFS, which was not statistically significant. In addition, CSC marker combination analysis, including CD $44^{+} / \mathrm{CD} 24^{-}$, exhibited a statistically significant association with RFS. These results were consistent with the findings of $\mathrm{Bi}$ et al (18), which revealed that the IHC results for $\mathrm{CD} 44^{+} / \mathrm{CD} 133^{+}$in medullary thyroid carcinoma are correlated with survival; in addition, CD $44^{+} / \mathrm{CD} 24^{-}$is associated with prognosis in patients with other types of cancer, such as breast (19).

At present, surgery, radiotherapy, chemotherapy and hormonal therapy are used to treat thyroid cancer; however, these treatments often exhibit limited efficacy. Conventional therapies target highly proliferating cells that form the majority of the tumor mass, but are ineffective against slowly proliferating or quiescent CSCs, which are responsible for drug resistance, metastasis and recurrence (20). However, the clinical importance of the presence of CSC markers, evaluated by IHC, remains uncertain. Due to their plasticity, whether the cells positive for these markers are actually CSCs is unknown. Even if IHC evaluation precisely reflects cancer stemness, the overall interpretation of such data is still challenging (19). However, it is beneficial for such efforts to be continued, since the ability to identify, isolate and study thyroid CSCs has a number of implications with potential novel therapeutic consequences.

In conclusion, the expression status of $\mathrm{CD}_{4} 4^{+}$and $\mathrm{CD} 24^{-}$in tissue samples was associated with RFS of patients with PTC. Particularly, the combination of $\mathrm{CD} 44^{+}$and $\mathrm{CD} 24^{-}$exhibited a significant association with RFS and gross extrathyroidal extension. Therefore, measuring CD $44^{+} / \mathrm{CD} 24^{-}$expression in order to evaluate the prognosis associated with RFS may be of use in PTC.

\section{Acknowledgements}

All data in the present study were reconstructed based on a master's thesis prepared by Dr Yoon-Jong Ryu under supervision of Professor Soon-Hyun Ahn (Department of Otorhinolaryngology Head and Neck Surgery, Seoul National University College of Medicine).

\section{Funding}

No funding was received.

\section{Availability of data and materials}

The datasets used and/or analyzed during the current study are available from the corresponding author on reasonable request.

\section{Authors' contributions}

YJR and SHA conceived and designed the study. YJR acquired and analyzed the data. JYC and KL contributed to the interpretation of the data. YJR and SHA wrote and revised the paper. JYC and KL provided administrative, technical, or material support. SHA supervised the study.

\section{Ethics approval and consent to participate}

The present study was approved by the Institutional Review Board at Seoul National University Bundang Hospital (approval no. B-1507/306-310). Written informed consent was waived due to the retrospective nature of the study.

\section{Patient consent for publication}

Not applicable.

\section{Competing interests}

The authors declare that they have no competing interests.

\section{References}

1. Ito Y, Nikiforov YE, Schlumberger M and Vigneri R: Increasing incidence of thyroid cancer: Controversies explored. Nat Rev Endocrinol 9: 178-184, 2013.

2. National_Cancer_Information_Center: Korea cancer registry statistics 2014. National Cancer Information Center, Goyang, 2016.

3. Cho BY, Choi HS, Park YJ, Lim JA, Ahn HY, Lee EK, Kim KW, Yi KH, Chung JK, Youn YK, et al: Changes in the clinicopathological characteristics and outcomes of thyroid cancer in Korea over the past four decades. Thyroid 23: 797-804, 2013.

4. Haugen BR, Alexander EK, Bible KC, Doherty GM, Mandel SJ, Nikiforov YE, Pacini F, Randolph GW, Sawka AM, Schlumberger M, et al: 2015 American thyroid association management guidelines for adult patients with thyroid nodules and differentiated thyroid cancer the American thyroid association guidelines task force on thyroid nodules and differentiated thyroid cancer. Thyroid 26: 1-133, 2016.

5. Moharil RB, Dive A, Khandekar S and Bodhade A: Cancer stem cells: An insight. J Oral Maxillofac Pathol 21: 463, 2017.

6. Ahn SH, Henderson YC, Williams MD, Lai SY and Clayman GL: Detection of thyroid cancer stem cells in papillary thyroid carcinoma. J Clin Endocrinol Metab 99: 536-544, 2014.

7. Fedchenko N and Reifenrath J: Different approaches for interpretation and reporting of immunohistochemistry analysis results in the bone tissue-a review. Diagn Pathol 9: 221, 2014. 
8. Perrier ND, Brierley JD and Tuttle RM: Differentiated and anaplastic thyroid carcinoma: Major changes in the American Joint Committee on Cancer eighth edition cancer staging manual. CA Cancer J Clin 68: 55-63, 2018.

9. Tubiana M, Schlumberger M, Rougier P, Laplanche A Benhamou E, Gardet P, Caillou B, Travagli JP and Parmentier C: Long-term results and prognostic factors in patients with differentiated thyroid carcinoma. Cancer 55: 794-804, 1985.

10. Coburn M, Teates D and Wanebo HJ: Recurrent thyroid cancer Role of surgery versus radioactive iodine (I131). Ann Surg 219: 587-595, 1994.

11. Kim WG, Kim EY, Yim JH, Han JM, Jeon MJ, Kim TY, Ryu JS, Gong G, Hong SJ, Kim WB and Shong YK: Comparison of different staging systems for predicting recurrence of papillary thyroid carcinoma. Endocrinol Metab 26: 53-61, 2011

12. Hwangbo Y, Kim JM, Park YJ, Lee EK, Lee YJ, Park DJ, Choi YS Lee KD, Sohn SY, Kim SW, et al: Long-term recurrence of small papillary thyroid cancer and its risk factors in a Korean multicenter study. J Clin Endocrinol Metab 102: 625-633, 2017.

13. Nagayama Y, Shimamura M and Mitsutake N: Cancer stem cells in the thyroid. Front Endocrinol (Lausanne) 7: 20, 2016.

14. Zito G, Richiusa P, Bommarito A, Carissimi E, Russo L, Coppola A, Zerilli M, Rodolico V, Criscimanna A, Amato M, et al: In vitro identification and characterization of CD133(pos) cancer Stem-like cells in anaplastic thyroid carcinoma cell lines. PLoS One 3: e3544, 2008.

15. Friedman S, Lu M, Schultz A, Thomas D and Lin RY: CD133+ anaplastic thyroid cancer cells initiate tumors in immunodeficient mice and are regulated by thyrotropin. PLoS One 4: e5395, 2009.

16. Sahlberg SH, Spiegelberg D, Glimelius B, Stenerlöw B and Nestor M: Evaluation of cancer stem cell markers CD133, CD44, CD24: Association with AKT isoforms and radiation resistance in colon cancer cells. PLoS One 9: e94621, 2014.
17. Tuttle RM, Haugen B and Perrier ND: Updated American Joint Committee on Cancer/Tumor-Node-Metastasis staging system for differentiated and anaplastic thyroid cancer (Eighth edition): What changed and why? Thyroid 27: 751-756, 2017.

18. Bi Y, Meng Y, Wu H, Cui Q, Luo Y and Xue X: Expression of the potential cancer stem cell markers CD133 and CD44 in medullary thyroid carcinoma: A ten-year follow-up and prognostic analysis. J Surg Oncol 113: 144-151, 2016.

19. Horimoto Y, Arakawa A, Sasahara N, Tanabe M, Sai S, Himuro T and Saito M: Combination of cancer stem cell markers CD44 and CD24 is superior to ALDH1 as a prognostic indicator in breast cancer patients with distant metastases. PLoS One 11: e0165253, 2016.

20. Eramo A, Haas TL and De Maria R: Lung cancer stem cells: Tools and targets to fight lung cancer. Oncogene 29: 4625-4635, 2010.

21. Amin MB, Greene FL, Edge SB, Compton CC, Gershenwald JE, Brookland RK, Meyer L, Gress DM, Byrd DR and Winchester DP: The eighth edition AJCC cancer staging manual: Continuing to build a bridge from a population-based to a more 'personalized' approach to cancer staging. CA Cancer J Clin 67: 93-99, 2017.

(F) $(9)$ This work is licensed under a Creative Commons Attribution-NonCommercial-NoDerivatives 4.0 International (CC BY-NC-ND 4.0) License. 